\title{
Influence of Purple Sweet Potato Powder Addition on the Quality Characteristics and Oxidative Stability of Cookies
}

\author{
Hai-Jung Chung \\ Department of Food Science and Nutrition, Daejin University, Gyeonggi 487-711, Korea
}

\begin{abstract}
Cookies were prepared by adding different levels $(0,5,10,15$, and $20 \%$ of purple sweet potato powder (PSPP) and their physicochemical and sensory characteristics were examined. With increase of the PSPP level, moisture content decreased and ash content increased $(p<0.05)$. The spread factor of control cookies was higher than that of cookies containing PSPP. The incoporation of PSPP in cookies lowered the lightness and yellowness but increased redness $(\mathbf{p}<\mathbf{0 . 0 5})$. Texture measurement showed that the addition of PSPP did not affect the hardness of cookies. Results of acceptance test revealed that overall acceptability score was not significantly different between the control and the PSPP added cookies. Therefore, it is suggested that PSPP can be incopporated into cookies up to $20 \%$ without affecting the cookie quality. Total polyphenol content and antioxidant activity were assessed to examine the functionality of cookies. In addition, substitution of wheat flour with PSPP yielded cookies with higher polyphenol content and antioxidative activity $(\mathbf{p}<0.05)$. The peroxide value (POV) and acid value increased during storage at $60^{\circ} \mathrm{C}$ for 80 days. The POV was significantly lower in cookies containing PSPP than the control cookies, suggesting that the addition of PSPP deterred the lipid oxidation $(\mathbf{p}<0.05)$.
\end{abstract}

Key words: purple sweet potato, cookies, antioxidant, polyphenol

\section{INTRODUCTION}

Purple sweet potatoes are a good source of antioxidants, dietary fiber, calcium, iron, and anthocyanins. Anthocyanins are a group of polyphenol compounds that are responsible for red, blue, purple colors in some fruits and vegetables (1). Recent studies indicated that anthocyanins have many biological functions $(2,3)$. Therefore, a diet rich in anthocyanin products has been shown to reduce the risk of developing chronic diseases and to improve visual functions (4). As the anthocyanins in the purple sweet potatoes are more stable than other anthocyanins in strawberry and red cabbage, purple sweet potatoes are a good source of stable anthocyanins as a natural colorant and as a biologically active food material (5).

Cookies are one of the most popular baked items consumed by all age groups. Cookies are appreciated for their taste, convenience, relatively low cost and longer shelf stability due to low moisture content. Recently, increasing consumer demand for healthy products has triggered the development of cookies with natural ingredients having specific functional properties. Many attempts have been made to improve cookies' nutritive value and functional properties by modifying their basic formulation. For example, flaxseed (6), lotus root pow- der (7), chlorella vulgaris (8), garlic juice (9), tomato powder (10), shredded garlic (11), brown rice flour (12), orange pulp (13), potato peel (14), and Chinese yam powder (15) were incorporated into the cookie formulation, and their quality characteristics were investigated.

The aim of the present work was to examine the possibility of improving the quality of cookies by replacing wheat flour with purple sweet potato powder (PSPP). Cookies were prepared by the addition of various levels of PSPP $(0,5,10,15$, and 20\%), and their physicochemical and sensory properties were investigated.

\section{MATERIALS AND METHODS}

\section{Materials}

Ingredients for cookies such as wheat flour (CJ Co., Korea), butter (Seoulmilk Co., Korea), sugar (CJ Co., Korea), egg and baking powder (Ruf, Germany) were purchased from a local market. Purple sweet potato was purchased as a powder form (100\%) which was cultivated in Haenam-gun in Jeonnam province.

\section{Chemicals}

1,1-Diphenyl-2-picrylhydrazyl (DPPH) was purchased from Sigma-Aldrich Chemical Co. (USA) and Folin- 
Ciocalteu reagent were purchased from Fluka (Switzerland). All other chemicals and solvents used were of analytical grade.

\section{Preparation of cookies}

Cookie dough formulation used in this study is shown in Table 1. Mixing ratios of PSPP to wheat flour were $0,5,10,15$, and $20 \%$. Egg, butter, and sugar were mixed in a hand mixer (62680, Proctor-Silex, USA) for $2 \mathrm{~min}$ to obtain a homogeneous cream. Flour, baking powder, and PSPP were sifted and added to the above cream and mixed for $30 \mathrm{sec}$. The dough was sheeted to a thickness of $5 \mathrm{~mm}$ thick with the roller and cut out with the help of cookie cutter having $50 \mathrm{~mm}$ diameter. The cookies were then transferred to a lightly greased baking tray and baked in an oven (FDO-7103, Daeyoung Co., Korea) at upper temperature of $170^{\circ} \mathrm{C}$ and lower temperature of $150^{\circ} \mathrm{C}$ for $14 \mathrm{~min}$. Cookies were allowed to cool at room temperature for $1 \mathrm{hr}$ before analysis.

\section{Proximate composition analysis}

Cookies were analyzed for moisture, crude protein, crude fat and ash content according to the methods described in AOAC (16).

\section{Evaluation of diameter, thickness and spread factor of} cookies

Diameter (D) of cookies was measured with the help of a ruler by laying six cookies edge-to edge. The cookies were rotated at an angle of $90^{\circ}$ and the diameter was remeasured and the average of one cookie was calculated in millimeter. Thickness (T) of cookies was measured by placing six cookies on top of one another and taking the average of one cookie in millimeter. The spread factor was determined by dividing diameter (D) with the thickness (T). Measurement was repeated three times.

\section{Color evaluation}

Surface color value of cookies was measured with a colorimeter (JX 777, Juki, Japan) calibrated with a white standard plate $(\mathrm{L}=+98.5, \mathrm{a}=+0.07, \mathrm{~b}=-0.40)$. Hunter $\mathrm{L}$

Table 1. Formula for cookies made with purple sweet potato powder

\begin{tabular}{cccccc}
\hline \multirow{2}{*}{$\begin{array}{c}\text { Ingredients } \\
(\%)\end{array}$} & S-0 & S-5 & S-10 & S-15 & S-20 \\
\cline { 2 - 6 } & 100 & 95 & 90 & 85 & 80 \\
\hline Flour & 0 & 5 & 10 & 15 & 20 \\
PSPP & 50 & 50 & 50 & 50 & 50 \\
Butter & 40 & 40 & 40 & 40 & 40 \\
Sugar & 20 & 20 & 20 & 20 & 20 \\
Egg & 1 & 1 & 1 & 1 & 1 \\
Baking power & 1
\end{tabular}

${ }^{1)} \mathrm{S}-0,0 \%$ substitution for flour; $\mathrm{S}-5,5 \%$ substitution for flour; S-10, 10\% substitution for flour; S-15, 15\% substitution for flour; S-20, 20\% substitution for flour. (lightness), a (redness), b (yellowness) values were measured. Color was measured from three different points per one cookie and three cookies were tested for each treatment. Average of these readings was taken for each set of samples.

\section{Measurement of cookie hardness}

Cookie hardness was measured using a rheometer (Compac-100, Sun Scientific Co., Japan) equipped with a $10 \mathrm{~kg}$ load cell in compression mode with a cylindrical aluminum plunger (diameter $5 \mathrm{~mm}$ ) at a table speed of $120 \mathrm{~mm} / \mathrm{min}$. An average of three values from different points per one cookie was taken and three cookies were selected at random for each treatment.

\section{Sensory evaluation}

Sensory characteristics of cookies prepared by the addition of PSPP were conducted. Cookie samples were placed on a plastic dish with different numbers to 8 trained panelists in the individual booth with lighting. Cookies were evaluated for surface color, sweet potato smell, savory taste, hardness and crispness on a 9-point scale with 9 indicating strong attributes. Acceptance test was performed by 33 untrained panelists. Samples were presented in random order and were asked to evaluate the consumer attributes of appearance and overall acceptability. A 9-point scale wherein 9=like extremely, $5=$ neither like nor dislike, $1=$ dislike extremely, was used.

\section{Detemination of polyphenol content and antioxidant} activity

The total polyphenol content and antioxidative activity were assessed to examine the functionality of cookies. Cookies were finely ground and extracted with 10 times of $80 \%$ ethanol $(\mathrm{w} / \mathrm{v})$ for $2 \mathrm{hr}$ at $37^{\circ} \mathrm{C}$ in a shaker. The samples were then centrifuged and the supernatant was used to evaluate the functionality. Total polyphenol content was determined by the Folin-Denis method (17) and calibration curve was made using tannic acid. Total polyphenol content of cookies were expressed as tannic acid equivalents (TAE). Antioxidant activity was measured using the DPPH method described by Blois (18).

\section{Detemination of oxidative stability}

Cookies were sealed in polyethylene bags and stored at $65^{\circ} \mathrm{C}$ for 80 days and the degree of lipid oxidation was measured. For such determination, lipid fraction of cookies was obtained by the Soxhlet method and peroxide value (POV) and acid value (AV) were measured according to the AOAC method (16).

\section{Statistical analysis}

The statistical analysis was performed using SAS (Statistical Analysis System, version 8.12). All data were 
recorded as mean \pm standard deviation of at least triplicate measurements. Means were compared with Duncan's multiple range test with $\mathrm{p}<0.05$.

\section{RESULTS AND DISCUSSION}

\section{Proximate composition}

The results of proximate composition of cookies are presented in Table 2. Moisture content of control was $5.77 \%$ and cookies made with 10,15 , and $20 \%$ PSPP had significantly lower values than control, which may be due to the lower moisture content of PSPP than wheat flour. In addition, the substitution of wheat flour with PSPP could dilute gluten network formation, resulting in a decrease in moisture retention. Crude protein contents were $9.37 \sim 10.62 \%$, and crude fat contents were $24.49 \sim 25.37 \%$, showing no significant differences between the control cookies and the four different treatments. Ash content of the control was $0.57 \%$ and increased with the increasing amount of PSPP $(\mathrm{p}<0.05)$, resulting in the highest value of $0.91 \%$ for the $20 \%$ PSPP. This is attributable to the higher ash content of PSPP than wheat flour.

\section{Diameter, thickness and spread factor of cookies}

The result of cookie diameter, thickness, and spread factor are shown in Table 3. Cookie diameter was decreased as the flour replacement was increased, but a trend with the mixing ratio of PSPP was not found above the $15 \%$. There were no significant differences in the thickness between the control and those containing
PSPP. The spread factor of cookies prepared with 5, 10, 15 , and 20\% PSPP was lower than that of control $(p<0.05)$. Ajila et al. (19) reported that the addition of mango peel powder at the level of 15 and $20 \%$ decreased the diameter and thickness of biscuits, and they suggested that such decrease was mainly due to dilution of gluten. In general, cookie spread or diameter is used as an indicator of cookie quality and cookies with larger diameter are considered more desirable (20). According to Han et al. (14), potato peel increased cookie diameter and spread ratio, and they proposed that such increases may be due to the higher moisture content in the cookie formula. Kim et al. (11) reported that the addition of shredded garlic significantly lowered the spread factor of cookies.

\section{Cookie color}

The results of Hunter L, a, and b values of cookies are shown in Table 4. The $\mathrm{L}$ value (lightness) of the control cookie was 81.53 and those of PSPP groups ranged from 51.82 to 68.79 . This indicates that the control cookie had the highest brightness, which decreased in proportion to the level of PSPP $(\mathrm{p}<0.05)$. Hunter a value (redness) of the control cookie was -2.05 and gradually increased as the PSPP addition increased, resulting in the highest value of 15.44 for the cookies containing $20 \%$ PSPP. This is attributable to the purplish color of PSPP. Hunter $b$ value (yellowness) of the control cookie was 28.68 and decreased with increasing PSPP level, showing the value of $8.48 \sim 16.97$ in the cookies contain-

Table 2. Proximate compositions of cookies made with purple sweet potato powder

\begin{tabular}{ccccc}
\hline Group $^{1)}$ & Moisture & Crude protein & Crude fat & Ash \\
\hline Purple sweet potato & $7.50 \pm 0.05^{2)}$ & $10.63 \pm 0.59$ & $0.97 \pm 0.10$ & $3.47 \pm 0.11$ \\
Wheat flour & $11.59 \pm 0.20$ & $9.51 \pm 0.45$ & $0.98 \pm 0.09$ & $0.45 \pm 0.11$ \\
\hline S-0 & $5.77 \pm 0.14^{\mathrm{c})}$ & $9.37 \pm 0.28^{\mathrm{a}}$ & $25.30 \pm 0.80^{\mathrm{a}}$ & $0.57 \pm 0.04^{\mathrm{a}}$ \\
S-5 & $5.68 \pm 0.14^{\mathrm{bc}}$ & $10.28 \pm 0.44^{\mathrm{a}}$ & $25.37 \pm 0.41^{\mathrm{a}}$ & $0.68 \pm 0.00^{\mathrm{b}}$ \\
S-10 & $5.52 \pm 0.01^{\mathrm{b}}$ & $10.21 \pm 0.29^{\mathrm{a}}$ & $24.80 \pm 0.29^{\mathrm{a}}$ & $0.74 \pm 0.01^{\mathrm{c}}$ \\
S-15 & $5.55 \pm 0.02^{\mathrm{b}}$ & $10.30 \pm 0.44^{\mathrm{a}}$ & $24.49 \pm 0.79^{\mathrm{a}}$ & $0.81 \pm 0.01^{\mathrm{d}}$ \\
S-20 & $4.94 \pm 0.03^{\mathrm{a}}$ & $10.62 \pm 0.58^{\mathrm{a}}$ & $24.50 \pm 0.57^{\mathrm{a}}$ & $0.91 \pm 0.12^{\mathrm{e}}$ \\
\hline
\end{tabular}

${ }^{1)}$ See the legend of Table 1 .

${ }^{2)}$ Each value is mean \pm standard deviation (SD).

${ }^{3)}$ Means with different letters within a column are significantly different from each other at $\alpha=0.05$ as determined by Duncan's multiple range test.

Table 3. Diameter, thickness, and spread factor of cookies made with purple sweet potato powder

\begin{tabular}{ccrrrr}
\hline Group $^{1)}$ & S-0 & S-5 & S-10 & S-15 & S-20 \\
\hline Diameter (mm) & $57.10 \pm 0.79^{2)(3)}$ & $54.74 \pm 1.31^{\mathrm{b}}$ & $52.17 \pm 1.05^{\mathrm{a}}$ & $51.42 \pm 0.42^{\mathrm{a}}$ & $51.05 \pm 0.79^{\mathrm{a}}$ \\
Thickness (mm) & $12.00 \pm 0.47^{\mathrm{a}}$ & $12.28 \pm 0.21^{\mathrm{a}}$ & $12.21 \pm 0.17^{\mathrm{a}}$ & $12.11 \pm 0.22^{\mathrm{a}}$ & $12.08 \pm 0.16^{\mathrm{a}}$ \\
Spread factor & $4.76 \pm 0.13^{\mathrm{b}}$ & $4.44 \pm 0.14^{\mathrm{a}}$ & $4.27 \pm 0.10^{\mathrm{a}}$ & $4.26 \pm 0.08^{\mathrm{a}}$ & $4.22 \pm 0.07^{\mathrm{a}}$ \\
\hline
\end{tabular}

${ }^{1)}$ See the legend of Table 1 .

${ }^{2}$ Each value is mean \pm SD.

${ }^{3)}$ Mean with different letters within a row are significantly different from each other at $\alpha=0.05$ as determined by Duncan's multiple range test. 
Table 4. Color value of cookies made with purple sweet potato powder

\begin{tabular}{cccc}
\hline Group $^{1)}$ & $\mathrm{L}$ & $\mathrm{a}$ & $\mathrm{b}$ \\
\hline S-0 & $81.53 \pm 1.5^{2) \mathrm{a} 3)}$ & $-2.05 \pm 0.29^{\mathrm{a}}$ & $28.68 \pm 1.20^{\mathrm{a}}$ \\
S-5 & $58.78 \pm 1.31^{\mathrm{b}}$ & $10.37 \pm 0.31^{\mathrm{b}}$ & $16.97 \pm 1.68^{\mathrm{b}}$ \\
S-10 & $52.41 \pm 1.20^{\mathrm{c}}$ & $13.46 \pm 0.25^{\mathrm{c}}$ & $12.88 \pm 1.05^{\mathrm{c}}$ \\
S-15 & $47.41 \pm 0.42^{\mathrm{d}}$ & $14.89 \pm 0.28^{\mathrm{d}}$ & $11.20 \pm 0.90^{\mathrm{c}}$ \\
S-20 & $43.95 \pm 0.58^{\mathrm{e}}$ & $15.44 \pm 0.15^{\mathrm{e}}$ & $8.48 \pm 0.58^{\mathrm{d}}$ \\
\hline
\end{tabular}

${ }^{1)}$ See the legend of Table 1 .

${ }^{2)}$ Each value is mean $\pm \mathrm{SD}$.

${ }^{3)}$ Means with different letters within a column are significantly different from each other at $\alpha=0.05$ as determined by Duncan's multiple range test.

ing PSPP. Therefore, it could be expected that the cookies with PSPP would become darker and reddish as the amount of PSPP increased. Similar results were obtained by Cho et al. (21) where the addition of sea tangle powder lowered the $\mathrm{L}$ and $\mathrm{b}$ value and increased the a value. Different results were obtained by Park et al. (22), where they reported that the $\mathrm{L}$, $\mathrm{a}$, and $\mathrm{b}$ values were lowered as the substitution level of Lycii fructus powder increased. Shin et al. (9) also reported that the incorporation of garlic juice in cookies decreased $\mathrm{L}$ value and increased a value, but had no effect on $b$ value. From these findings, it is suggested that the surface color of the cookies was influenced by both the amount and the type of the flour replacement.

\section{Cookie hardness}

The result of cookie hardness is presented in Table 5. The hardness value of the control cookie was 78.7 $\mathrm{kg} / \mathrm{cm}^{2}$ and that of PSPP added groups exhibited the range of $85.8 \sim 96.3 \mathrm{~kg} / \mathrm{cm}^{2}$. The highest value was obtained for the $20 \%$ added group, yet no significant differences among the treatments were observed. Similar results were obtained by Singh et al. (23), where they re- ported that the incorporation of gluten-soy protein blends had no effect on cookie hardness. Different results were found by Kim et al. (24) where the addition of barley germ resulted in a decrease in hardness. Yoon et al. (25) reported that the addition of soybean paste powder increased hardness of cookies. Hardness is an important aspect of cookie quality and affects handling, shelf life, and consumer acceptance (26). From the results of many studies on the hardness profile of cookies, it is suggested that the incorporation of different ingredients into cookies exhibited different hardness profile.

\section{Sensory evaluation}

Table 6 shows the results of sensory evaluation of cookies made with PSPP. The surface color was evaluated to become darker as the PSPP level increased, which is due to the purplish color of PSPP. This is in agreement with the result of lightness value shown in Table 4. Sweet potato smell and savory taste were significantly affected by the addition of PSPP because PSPP gave a characteristic flavors $(p<0.05)$. Every increment in the amount of flour substitution resulted in cookies with more intense sweet potato smell and savory taste, showing the highest scores in cookies containing 20\% PSPP. The hardness score was highest for the $20 \%$ PSPP cookies, but there was no remarkable differences among the rest of the groups. The crispness score was the highest for the control cookies, followed by the one containing $20 \%$ PSPP $(p<0.05)$. Table 7 shows the results of consumer test and appearance and overall acceptability were not significantly different between the control cookies and those containing PSPP. Therefore, replacing up to $20 \%$ wheat flour with PSPP would not give any significant adverse effect on cookie acceptability.

Table 5. Hardness value of cookies made with purple sweet potato powder

\begin{tabular}{cccccc}
\hline Group $^{1)}$ & S-0 & S-5 & S-10 & S-15 & S-20 \\
\hline Hardness & $78.7 \pm 15.9^{2)}$ & $86.3 \pm 10.5$ & $85.8 \pm 6.5$ & $87.9 \pm 13.2$ & $93.3 \pm 12.9$ \\
\hline
\end{tabular}

${ }^{1)}$ See the legend of Table $1 .{ }^{2)}$ Each value is mean \pm SD.

Table 6. Sensory scores of cookies made with purple sweet potato powder

\begin{tabular}{cccccc}
\hline Group $^{1)}$ & Surface color & Sweet potato smell & Savory taste & Hardness & Crispness \\
\hline S-0 & $4.33 \pm 1.08^{2) \mathrm{a} 3)}$ & $0.94 \pm 0.24^{\mathrm{a}}$ & $1.00 \pm 0.34^{\mathrm{a}}$ & $5.44 \pm 1.46^{\mathrm{a}}$ & $6.78 \pm 0.73^{\mathrm{c}}$ \\
S-5 & $5.33 \pm 1.03^{\mathrm{b}}$ & $4.06 \pm 1.07^{\mathrm{b}}$ & $3.94 \pm 1.06^{\mathrm{b}}$ & $5.22 \pm 0.88^{\mathrm{a}}$ & $5.28 \pm 0.83^{\mathrm{a}}$ \\
S-10 & $6.28 \pm 0.96^{\mathrm{c}}$ & $4.61 \pm 1.21^{\mathrm{b}}$ & $4.11 \pm 0.96^{\mathrm{c}}$ & $5.33 \pm 1.14^{\mathrm{a}}$ & $5.00 \pm 1.19^{\mathrm{a}}$ \\
S-15 & $7.11 \pm 0.83^{\mathrm{d}}$ & $5.61 \pm 1.03^{\mathrm{c}}$ & $5.89 \pm 1.23^{\mathrm{d}}$ & $5.56 \pm 1.15^{\mathrm{a}}$ & $5.39 \pm 0.85^{\mathrm{ab}}$ \\
S-20 & $8.00 \pm 0.91^{\mathrm{e}}$ & $6.94 \pm 1.05^{\mathrm{d}}$ & $6.72 \pm 1.78^{\mathrm{e}}$ & $6.50 \pm 1.42^{\mathrm{b}}$ & $6.00 \pm 1.33^{\mathrm{b}}$ \\
\hline
\end{tabular}

${ }^{1)}$ See the legend of Table 1 .

${ }^{2}$ Each value is mean $\pm \mathrm{SD}$.

${ }^{3)}$ Means with different letters within a column are significantly different from each other at $\alpha=0.05$ as determined by Duncan's multiple range test. 
Table 7. Acceptance test of cookies made with purple sweet potato powder

\begin{tabular}{cccccc}
\hline Group $^{1)}$ & S-0 & S-5 & S-10 & S-15 & S-20 \\
\hline Appearance & $6.21 \pm 0.93^{2)}$ & $5.62 \pm 1.52$ & $5.86 \pm 1.37$ & $6.00 \pm 1.45$ & $6.19 \pm 1.86$ \\
Overall acceptability & $6.06 \pm 0.98$ & $5.99 \pm 1.05$ & $6.13 \pm 1.08$ & $6.09 \pm 1.06$ & $5.92 \pm 1.45$ \\
\hline
\end{tabular}

${ }^{1)}$ See the legend of Table $1 .{ }^{2)}$ Each value is mean \pm SD.

Table 8. Total polyphenol content and radical scavenging activity in cookies made with purple sweet potato powder

\begin{tabular}{cccccr}
\hline Group $^{1)}$ & S-0 & S-5 & S-10 & S-15 & S-20 \\
\hline Radical scavenging activity (\%) & $9.66 \pm 3.66^{2) \mathrm{a} 3)}$ & $31.32 \pm 4.10^{\mathrm{b}}$ & $70.90 \pm 8.32^{\mathrm{c}}$ & $78.30 \pm 4.54^{\mathrm{c}}$ & $84.00 \pm 1.38^{\mathrm{c}}$ \\
Total polyphenol content (mg TAE/100 g) & $34.65 \pm 6.22^{\mathrm{a}}$ & $52.91 \pm 5.40^{\mathrm{b}}$ & $72.03 \pm 8.71^{\mathrm{c}}$ & $91.73 \pm 6.53^{\mathrm{d}}$ & $134.43 \pm 7.65^{\mathrm{e}}$ \\
\hline
\end{tabular}

${ }^{1)}$ See the legend of Table 1 .

${ }^{2)}$ Each value is mean \pm SD.

${ }^{3}$ Means with different letters within a row are significantly different from each other at $\alpha=0.05$ as determined by Duncan's multiple range test.

\section{Evaluation of functional properties of cookies}

The total polyphenol content and antioxidative activity were assessed to examine the functionality of cookies. As shown in Table 8, substitution of wheat flour with PSPP resulted in a significant increase in polyphenol content as the PSPP level increased $(\mathrm{p}<0.05)$. The polyphenol content was $34.65 \mathrm{mg} \mathrm{TAE} / 100 \mathrm{~g}$ in control and $134.43 \mathrm{mg} \mathrm{TAE} / 100 \mathrm{~g}$ in cookies with $20 \%$ PSPP, which is about 4-fold increase by replacement with PSPP.

Incorporation of PSPP in cookies yielded higher antioxidant activity than the control $(\mathrm{p}<0.05)$. Radical scavenging activity of the control was $9.66 \%$, while those of $5,10,15$, and $20 \%$ PSPP groups exhibited 31.32 , $70.90,78.30$, and $84.00 \%$, respectively. From these findings, it is clear that the incorporation of PSPP in cookies increased the total polyphenol content, thus contributing the increase in antioxidant properties.

\section{Oxidative stability of cookies during storage}

The changes in the POV during storage at $65^{\circ} \mathrm{C}$ for 80 days are shown in Fig. 1. POV increased in all groups with time during storage. After 40 days of storage, control cookie showed $8.21 \mathrm{meq} / \mathrm{kg}$, while cookies containing PSPP ranged from 4.22 to $4.88 \mathrm{meq} / \mathrm{kg}$. After 80 days of storage, cookies prepared with PSPP had lower POV of $8.68 \sim 17.04 \mathrm{meq} / \mathrm{kg}$ than the control cookies $(\mathrm{p}<0.05)$. The lowest value was observed in cookies with $20 \%$ addition, followed by $15 \%, 10 \%$ and $5 \%$. The incorporation of PSPP in cookies increased the degree of inhibition of peroxide formation and this is related to the polyphenols present in PSPP (shown in Table 8), which may act as a natural antioxidant and improve the shelf life of the cookies.

The changes in the AV during storage are shown in Fig. 2. AV increased during storage. After 80 days, AV ranged from 1.41 to 1.89 . The highest value was observed for the control cookies, while the lowest values

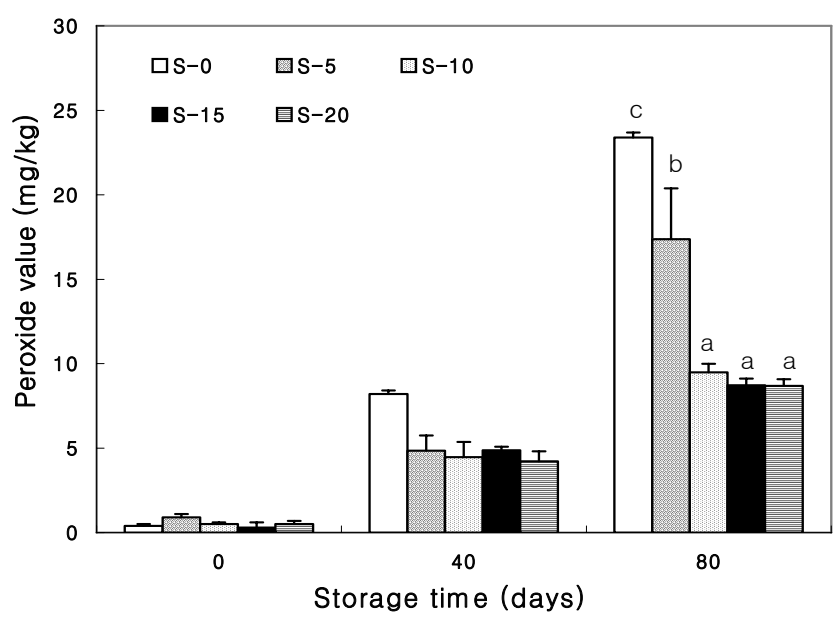

Fig. 1. Changes in peroxide value of cookies made with purple sweet potato powder during storage at $60^{\circ} \mathrm{C}$ for 80 days. S- $0,0 \%$ substitution for flour; S-5, 5\% substitution for flour; S-10, 10\% substitution for flour; S-15, 15\% substitution for flour; S-20, $20 \%$ substitution for flour.

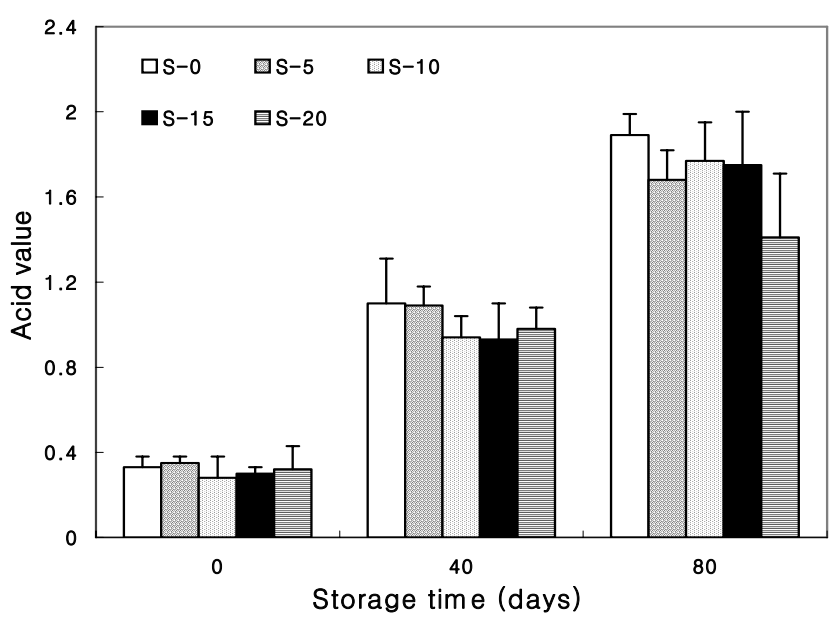

Fig. 2. Changes in acid value of cookies made with purple sweet potato powder during storage at $60^{\circ} \mathrm{C}$ for 80 days. S- $0,0 \%$ substitution for flour; S-5, $5 \%$ substitution for flour; S-10, 10\% substitution for flour; S- $15,15 \%$ substitution for flour; S-20, 20\% substitution for flour. 
were found for the cookies prepared with 20\% PSPP, but no significant differences were found among treatments. Kim et al. (24) reported that cookies with $20 \%$ barley germ substitution had higher acid value but lower peroxide value than the control during storage at $60^{\circ} \mathrm{C}$ for 30 days. Cho et al. (21) also reported that cookies made with sea tangle powder of $3 \%$ and $6 \%$ showed lower acid value, peroxide value, and thiobarbituric acid value than $9 \%$ addition and the control cookies.

\section{ACKNOWLEDGEMENT}

This work was supported by the Daejin University Research Grants in 2008.

\section{REFERENCES}

1. Wu DM, Lu J, Zheng YL, Zhou Z, Shan Q, Ma DF. 2008 Purple sweet potato color repairs D-galactose-induced spatial learning and memory impairment by regulating the expression of synaptic proteins. Neurobiol Learn Memory 90: 19-27.

2. Shih PH, Yeh CT, Yen GC. 2007. Anthocyanins induce the activation of phase II enzymes through the antioxidant response element pathway against oxidative stress-induced apoptosis. J Agric Food Chem 50: 1672-1676.

3. Kano M, Takayanagi T, Harada K, Makino K, Ishikawa F. 2005. Antioxidative activity of anthocyanins from purple sweet potato, Ipomoea batatas cultivar Ayamurasaki. Biosci Biotechnol Biochem 69: 979-988.

4. Hou DX. 2003. Potential mechanisms of cancer chemoprevention by anthocyanins. Curr Mol Med 3: 149-159.

5. Zhang ZF, Fan SH, Zheng YL, Lu J, Wu DM, Shan Q, $\mathrm{Hu}$ B. 2008. Purple sweet potato color attenuates oxidative stress and inflammatory response induced by D-galactose in mouse liver. Food Chem Toxicol 47: 496-501.

6. Hussain S, Anjum FM, Butt MS, Khan MI, Asghar A. 2006. Physical and sensoric attributes of flaxseed flour supplemented cookies. Turk J Biol 20: 87-92.

7. Song YH, Lee JH, Jeong HS, Park SH, Jung HA, Joo N. 2008. Optimization of iced cookie with dried lotus root powder using response surface methodology. J Food Sci Nutr 13: 340-347.

8. Gouveia L, Batista AP, Mirand A, Empis J, Raymundo A. 2007. Chlorella vulgaris biomass used as colouring source in traditional butter cookies. Innov Food Sci Emerg Technol 8: 433-436.

9. Shin JH, Lee SJ, Choi DJ, Kwen OC. 2007. Quality characteristics of cookies with added concentrations of garlic juice. Korean J Food Cookery Sci 23: 609-614.
10. Chung HJ. 2007. Quality attributes of cookies prepared with tomato powder. J Food Sci Nutr 12: 229-233.

11. Kim HYL, Jeong SJ, Heo MY, Kim KS. 2002. Quality characteristics of cookies prepared with varied levels of shredded garlics. Korean J Food Sci Technol 34: 637-641.

12. Lee MH, Oh MS. 2006. Quality characteristics of cookies with brown rice flour. Korean J Food Culture 221: 685-694

13. Larrea MA, Chang YK, Martinez-Bustos F. 2005. Some functional properties of extruded orange pulp and its effect on the quality of cookies. LWT 38: 213-220.

14. Han JS, Kim JA, Han GP, Kim DS. 2004. Quality characteristics of functional cookies with added potato peel. Korean J Soc Food Cookery Sci 20: 607-613.

15. Chung KM, Kwon CS. 1999. Properties of cookies added of flour and Chinese yam powder. Food Sci Biotechnol 8: $341-343$.

16. AOAC. 1995. Official Methods of Analysis of AOAC. 16th ed. Association of Official Analytical Chemists, Washington DC, USA.

17. Teresa-Sartue M, Huang SW, Frankel EN. 1995. Effect of natural antioxidants in virgin olive oil on oxidative stability of refined, bleached and deodorized olive oil. $J$ Am Oil Chem Soc 72: 1131-1137.

18. Blois MS. 1958. Antioxidant determination by the use of a stable free radical. Nature 181: 1199-1200.

19. Ajila CM, Leelavathi K, Prasada Rao UJS. 2008. Improvement of dietary fiber content and antioxidant properties in soft dough biscuits with the incorporation of mango peel powder. J Cereal Sci 48: 319-326.

20. Fimney KF, Morris VH, Yamazaki WT. 1950. Micro versus macro cookie baking procedures for evaluating the cookie quality of wheat varieties. Cereal Chem 27: 42-49.

21. Cho HS, Park BH, Kim KH, Kim HA. 2006. Antioxidative effect and quality characteristics of cookies made with sea tangle powder. Korean J Food Culture 21: 541-549.

22. Park BH, Cho HS, Park SY. 2005. A study on the antioxidative effects and quality characteristics of cookies made with Lycii fructus powder. Korean J Food Cookery Sci 21: 94-102.

23. Singh J, Singh N, Sharma TR, Saxena SK. 2003. Physicochemical, rheological and cookie making properties of corn and potato flours. Food Chem 83: 387-393.

24. Kim IS, Lee YT, Seog HM. 2002. Effects of barley germ on sugar-snap cookie quality. Food Sci Biotechnol 11: 515-519.

25. Yoon HS, Joo SJ, Kim KS, Kim SJ, Kim SS, Oh MH. 2005. Quality characteristics on cookies added with soybean paste powder. Korean J Food Preserv 12: 432-435.

26. Agyare KK, Addo K, Xiong YL, Akoh CC. 2005. Effect of structured lipid on alveograph characteristics, baking and textural qualities of soft wheat flour. J Cereal Sci 42: 309-316.

(Received January 28, 2009; Accepted March 9, 2009) 